\title{
CORRELATION BETWEEN THE FIVE PERSONALITY DIMENSIONS AND CREATIVE BEHAVIOURS OF ELECTRICAL AND ELECTRONICS TEACHERS IN NIGERIAN TECHNICAL COLLEGES
}

\author{
Raymond, E. ${ }^{1}$, Uduafemhe, E. M. ${ }^{1}$, Alome, S. A. ${ }^{2}$, \& \\ Ogumah, B. A. O. ${ }^{3}$ \\ ${ }^{1}$ Department of Industrial and Technology Education, Federal University of Technology, \\ Minna, Niger State, Nigeria. \\ ${ }^{2}$ Department of Examination Development, National \\ Examinations Council, Minna, Nigeria. \\ ${ }^{3}$ Department of Electrical/Electronics Technology, Federal College of Education (Technical) \\ Gombe, Gombe State.
}

Correspondence author email: maxwelluduafemhe@gmail.com

Received August 29 $9^{\text {th }}, 2018$; accepted November $4^{\text {th }}, 2018$

\begin{abstract}
This study determined the correlations between the five personality dimensions and the creative behaviours of electrical and electronics teachers in Nigerian Technical Colleges. Multiple prediction research design was adopted for the study. Purposive sampling technique was used to select 94 electrical and electronics teachers from a population of 137 persons teaching electrical and electronics trades in the 21 technical colleges in North-western Nigeria. The data for the study were collected using two instruments: Kaufman Domains of Creativity Scale which consists of 50 items in which participants rated themselves on a scale of 1 to 5 in comparison to other people in their age and experience, and Goldberg's Big Five Inventory which is a 44 item, five point Likert scale type of; Strongly Disagree, Disagree, Neutral, Agree, and Strongly Agree. To account for socio-cultural differences, the instruments were subjected to a pilot study in Niger State, North-central Nigeria, and their reliability coefficients were found to be 0.86 and 0.83 respectively. The data were analysed using Pearson Product Moment Correlation and Multiple Regression. Results revealed that there is a correlation between the five personality dimensions when treated together and the creative behaviours of electrical and electronics teachers. Also, the personality dimensions treated together significantly correlate with the creative behaviours of the teachers. It was concluded that personality traits are important for creative behaviours of trade's teachers. Hence, a reward and incentive systems should be put in place, for the encouragement of creativity among electrical and electronics teachers in technical colleges in Nigeria.
\end{abstract}

Keywords: Personality traits; creative behaviours; teacher reward system; regression analysis DOI: https://10.30880/jtet.2018.10.02.003 


\section{INTRODUCTION}

Human beings are considered to be higher animals (Kolstad, 2013), and so their brain function is far above all other animals which is why it is difficult to use a few words to sum up the thoughts and behaviour of a person or a group. Owing to this fact, no one is certain of how a person will act at every point in time. The reason for this is that the actions and thoughts of a person are driven by biological, physiological and emotional forces which may be internal or external, and so these forces determine the way he relates with others (Corr \& Matthews, 2009). In an attempt to explain human behaviours, scientists have used some constructs to describe human beings. One of such constructs is personality. Personality may be defined as the set of psychological traits and mechanisms inside a person that are ordered and comparatively permanent and that inspire his or her interface with, and adjustments to the intrapsychical, physical, and human interactive atmospheres (Larsen \& Buss, 2005). Personality could also be referred to a person's distinctive formation of way of thinking, passion, and conduct, in addition to the mental contrivances - covert or overt - at the back those formations (Funder, 2004). Although, the meaning of personality has been presented by different scholars in different ways, what is common in all the definitions presented is that personality is a system of parts that is organized, developed, and is expressed in a person's actions. The personality of an individual is responsible for the differences in characteristic patterns of thinking, feeling and behaving with another person (American Psychological Association, APA, 2018). It is the study of personality that gives insights and clearer understanding of individual differences in particular, differences in personality characteristics, such as sociability or irritability which birthed the five personality dimensions, also referred to as the big five personality traits or the five factor model (Gurven et al., 2013; Zaidi et al., 2013; Widiger \& Costa, 2012).

The five personality dimensions have come to be one of the most prominent models for describing personality. In agreement with this, Zaidi et al. (2012) revealed that "within the last two decades, there has been consensus within the organization behaviour researchers that five factor model of personality, often termed the "big five" personality framework is one of the most prominent models in contemporary psychology to describe the most salient features of personality". To Mendonca (2016), five personality dimensions represent personality at the broadest level of abstraction. This is because each dimension summarizes a large number of distinct, more specific, personality characteristics (Zaidi et al., 2012). The five personality dimensions are five clusters of habitual behaviours: conscientiousness, agreeableness, extroversion/introversion, openness to experience, and emotional stability (Mendonca, 2016; Stajkovic, Bandura, Locke, Lee, \& Sergent, 2018). Soto and Jackson (2013) noted that five personality dimensions is a set of five broad trait dimensions or domains, often referred to as the "Big Five": Extraversion, Agreeableness, Conscientiousness, Neuroticism and Openness to Experience.

Extraversion is the propensity to be friendly, firm, vigorous, bubbly, jovial, enthusiastic, and chatty (Stajkovic et al., 2018). Ashraf, Bano, Ilyas, and Rehman (2013) argued that extroversion is one of the five core traits believed to make up human personality. It is essentially characterized by friendliness, chattiness, firmness and excitability. People who are high in extroversion have the tendency to seek out societal motivation and occasions to connect to other people, for this reason extroverts are often described as being full of life, energy and positivity (Ashraf et al., 2013). Agreeableness is the tendency of a person to be kind, approachable, tactful, have a positive assessment of people in general and get along well with others. According to Zaidi et al. (2012), agreeableness is the propensity to be believing, submissive, considerate, selfless, lavish, and gentle. Zaidi et al. further remarked that people with high agreeableness score have an optimistic view of human nature. In essence, agreeable people are sympathetic to others and have a desire to help others; and expect others to be replicate their gestures. Conscientiousness is another important trait in the five personality dimensions. Conscientious individuals have the tendency to act dutifully, show selfdiscipline, and aim for achievement against a measure or outside expectation. According to McCrae and Löckenhoff (2010), conscientiousness is a personality trait that is characterized by organization, purposeful action, self-discipline, and a drive to achieve. Zaidi et al. (2012) intimated that 
conscientiousness is a personality trait that describes socially prescribed impulse control that facilitates task and goal-directed behaviour, such as thinking before acting, delaying gratification, following norms and rules, and planning, organizing, and prioritizing tasks. Neuroticism is one of the more well established and empirically validated personality trait domains, with a substantial body of research to support its heritability, childhood antecedents, temporal stability across the life span, and universal presence (Widiger \& Oltmanns, 2017). Based on the submission of Zaidi et al. (2012), neuroticism is a personality trait that measures the continuum between emotional adjustment and emotional maladjustment.

It was further posited that people at the high end of neuroticism have the tendency to experience fear, nervousness, sadness, tension, anger, and guilt (Zaidi et al., 2012). Hence, people at the low end of neuroticism are often noted to be emotionally stable and even-tempered. Openness to experience is one of the traits used to describe human personality in the five personality dimensions which involves active imagination (fantasy), aesthetic sensitivity, attentiveness to inner feelings, preference for variety, and intellectual curiosity. Openness is generally characterized as a dimension of personality reflecting the tendency toward cognitive exploration (Kaufman, Quilty, Grazioplene, Hirsh, Gray, Peterson \& DeYoung, 2016). Openness to experience is the tendency of the individual to be imaginative, sensitive, original in thinking, attentive to inner feelings, appreciative of art, intellectually curious, and sensitive to beauty (Zaidi et al., 2012; Krishnan, Ismail, Loon \& Muthusamy, 2017). Individuals possessing openness to experience have a high tendency to be willing to welcome new ideas and progressive ideals. Studies have linked these five personality traits with many constructs in fields of human endeavour.

Research evidences pointing to the correlation of the five personality dimensions with other constructs abound in research space. For instance, Bui (2017), Templer (2012) and Furnham, Eracleous and Chamorro-Premuzic (2009) reported that there is a significant correlation between personality traits and job satisfaction. The five personality dimensions have an influence on attitude to work (Matteson \& Kennedy, 2016; Wille, Hofmans, Feys \& De Fruyt, 2014; Bettencourt, Gwinner, \& Meuter, 2001). O’Sullivan, Strauser and Wong (2012) reported that personality accounts for a significant amount of variance in work behaviour efficacy. Also, Stajkovic et al. (2018) reported that the big five personality traits influence self-efficacy and academic performance.

Furthermore, the five personality dimensions have been found to correlate with creative behaviour of workers in different field. Such field include; the military (Darr, 2009), the police (Madamet, Potard, Huart, El-Hage, \& Courtois, 2017), students (O’Connell \& Sheikh, 2011) and teachers in the social science (Bandura, 2012). There is a link between personality and individual creative behaviour in the workplace (Yesil \& Sozbilir, 2013). Similarly, Karwowski, Lebuda, Wisniewska, and Gralewski (2013) demonstrated that creative behaviour is associated with all five personality dimensions. Ivcevic and Mayer (2006) identified five types of individuals based on the profiles of creative activities in which they participated. These were conventional, everyday creative individuals, artists, scholars, and renaissance individuals. Creativity is important for the progress of every field of human endeavour. It helps them to avoid predictability (Misrah \& Singh, 2010). Creativity is the bedrock of creative behaviour.

Creative behaviour is a human characteristic referring to a behaviour that produces things that are novel or useful to either an individual or a society. Maher, Merrick and Saunders (2008) posited that creative behaviour in humans, may be defined as behaviour that brings a unique product into being that is valuable to either an individual or a society. Creative behaviour is a process involving imagination, originality (the ability to come up with ideas and products that are new and unusual), productivity (the ability to generate a variety of different ideas through divergent thinking), problem solving (application of knowledge and imagination to a given situation), and the ability to produce an outcome of value and worth (Sharp, 2004). In essence, creative behaviour is a result of extrinsic and intrinsic motivation, adaptation, novelty, behavioural diversity, emergence and learning (Maher, Merrick \& Saunders, 2008; Grant \& Berry, 2011). Patterson, Kerrin and Gatto-Roissard (2009) submitted that there several characteristics that are associated with creative behaviour. They are: 
imagination, inquisition, high energy, high desire for autonomy, social rule independence and high self-confidence. The personal characteristics that related to creative behaviour include: selfmotivation, special cognitive abilities, a risk orientation, diverse experience, expertise in the area, social skill, brilliance and naiveté. (Setiadi \& Aryanto, 2014). Creative behaviour can be learnt, taught and adapted (Sharp, 2004; Maher, Merrick \& Saunders, 2008). Creative behaviour is linked to success in work place (Anderson, Potočnik \& Zhou, 2014; Stanley, 2016). Vasudevan (2013) hinted that teachers' creative behaviour are considered as key factors in the success of the educational reform, because it heavily impacts the willingness of teachers' to involve in cooperative, reflective and critical practice to develop students' expertise in school subjects. This therefore could have some implications for electrical and electronics teachers in technical colleges.

An electrical and electronics teacher is a person who has been trained up to a degree level under the technology education programme as stipulated in the national policy on education (Federal Republic of Nigeria (FRN), 2013, p. 31), and teaches at least one electrical and electronics trade in a technical college. The discipline taught by electrical and electronics teachers are referred to as electrical and electronics trades. Electrical and electronics trades, as they are called, are among the main trade areas offered at the technical college level of the Nigerian educational system. According to Emesini (2016) and FRN (2013) the trades that fall under Electrical and electronics trades include: Electrical Installation and Maintenance Works, Radio, Television and Electronic Servicing, Refrigeration and Air-conditioning, GSM Maintenance and Repairs, and Computer Maintenance and Instrument Mechanics. The expected skills of electrical and electronics graduates of a technical college (irrespective of their specialization) include measuring and cutting of metals, interpretation of circuit diagrams, carrying out basic electricity calculations, understanding of the working principles and applications of various electrical and electronics devices, troubleshooting of electrical and electronics systems, installation of electrical and electronics systems and production of electrical and electronics drawing (National Board for Technical Education (NBTE), 2001). Okwelle and Okeke (2012) stated that the technical college electrical and electronics trades curricula among others are aimed at training skilled technical manpower equipped with the necessary technical knowledge and practical skills for installing electrical power systems as well as diagnosing and repairing faults in electronics systems. The work schedule of an electrical and electronics teacher entails that he interacts with his students and the subject matter. To be a successful and effective teacher, it is incumbent that the electrical and electronics teacher factors in creativity in order to facilitate successful learning experiences among his students in the technical college.

A technical college is post-primary institution that impart the necessary skills leading to the production of craftsmen and technicians who are enterprising and self-reliant (FRN, 2013). There are three main objectives the technical colleges in Nigeria were designed to achieve namely; the graduates would be able to (a) secure employment either at the end of the whole course or after completing one or more modules of employable skills; (b) set up their own businesses and become self-employed and be able to employ others; and (c) pursue further education in advance craft/technical programmes and in post-secondary (tertiary) technical institutions such as polytechnics or colleges of education (technical) and universities (FRN, 2013). There are two main programmes offered in the technical college system in Nigeria. These are: National Technical Certificate (NTC) which spans over a period of three years, and Advanced National Technical Certificate (ANTC) which last one year (NBTE, 2001). Although, the five personality dimensions as well as creative behaviour were earlier noted to correlated strongly in a number of professions, it is however not certain whether they correlate as strongly among electrical and electronics teachers at the technical college level. It is against this background that this study sought to determine the correlation between the five personality dimensions and creative behaviours of electrical and electronics teachers in Nigerian technical colleges.

Hence, the aim of this study was to correlate the five personality dimensions with the creative behaviours of electrical and electronics teachers in Nigerian technical colleges. Specifically, the study was designed to determine: if there is a correlation between the five personality dimensions when treated together and the creative behaviours of electrical and electronics teachers in technical colleges 
in Nigeria, and if there is a correlation between the five personality dimensions when treated separately and the creative behaviours of electrical and electronics teachers in technical colleges in Nigeria.

\section{RESEARCH METHODOLOGY}

Multiple prediction research design was used for this study. Multiple prediction design is a high order correlational research design that extends the least-square association principle to the study of relationship between one dependent variable and two or more independent variables (Iruloh \& Ukaegbu, 2015). The design was considered appropriate for use in this study because the study involves one dependent variable (creative behaviour) and five independent variables of the five personality dimensions: Extraversion, Agreeableness, Openness, Conscientiousness and Neuroticism. Purposive sampling technique was used to select 94 electrical and electronics teachers out of the 137 persons teaching electrical and electronics trades in the 21 technical colleges in North-western Nigeria. North-western Nigeria is made up of Kaduna, Kano, Jigawa, Katsina, Zamfara, Sokoto and Kebbi States. Purposive sampling was necessary because not all the people teaching electrical electronics trades in the 21 technical colleges were electrical and electronics technology teachers by training.

Two instruments; Kaufman Domains of Creativity Scale (K-DOCS) and Goldberg's Big Five Inventory (BFI) were used for data collection in the study. Kaufman Domains of Creativity Scale (KDOCS) was used to determine participants' level of creative behaviour. It consists of 50 items in which participants rated themselves on a scale of 1 to 5 in comparison to other people in their age and experience. The coding for this instrument were interpreted as follows: 1 (much less creative), 2 (less creative), 3 (neither more nor less creative), 4 (more creative), and 5 (Much more creative). Goldberg's Big Five Inventory (G-BFI) on the other hand is an instrument for measuring the five personality dimensions of people. G-BFI is a 44 item instrument modified by the researchers into a five point likert type scale of; $1=$ Strongly Disagree, $2=$ Disagree, $3=$ Neutral, $4=$ Agree, $5=$ Strongly Agree. The instruments are standardized, meaning that they have been validated by their developers (Kaufman, 2012; Iruloh \& Ukaegbu, 2015). However, to account for cultural and social differences, the two instruments were subjected to a pilot study in Niger State, North-central Nigeria. The reliability coefficients were found to be 0.86 and 0.83 respectively.

The instruments were administered with the help of seven research assistants. Copies of the instruments were mailed to the research assistants through the bus terminus in Minna, Niger State. Administered instrument were returned to the researchers in the same manner. Statistical Package for the Social Science (SPSS) version 22 was used to carry out all statistical calculations. Pearson's Product Moment Correlation and multiple regressions were used to analyse the data for study. The research questions were analysed using Pearson's Product Moment Correlation. The hypotheses were however tested at a probability level of 0.05 using multiple regressions.

\section{RESULTS}

Analysis and presentation of data are ordered according to the research questions and hypotheses that guided the study.

\subsection{Pearson correlations between the five personality dimensions when treated together and the creative behaviours of electrical and electronics teachers}

The data presented in Table 1 provides information for answering research question one. The correlation analysis between the five personality dimensions when treated together and the creative behaviours of electrical and electronics teachers in technical colleges show that with $r=0.89$ at $p<$ .05 , there is high correlation between the two constructs. Hence, there is a correlation between the five 
personality dimensions when treated together and the creative behaviours of electrical and electronics teachers in technical colleges in Nigeria.

Table 1: Correlation analysis between the five personality dimensions when treated together and the creative behaviours of electrical and electronics teacher is technical colleges

\begin{tabular}{lccccc}
\hline \multicolumn{1}{c}{ Variable } & Mean & SD & N & R & Remark \\
\hline G-BFI & 3.58 & 0.57 & 94 & 0.89 & S \\
K-DOCS & 3.61 & 0.53 & 94 & & \\
\hline
\end{tabular}

** Correlation is significant at the 0.05 level (2-tail). $\mathrm{N}=$ Number of respondents, $\mathrm{SD}=$ Standard Deviation, and $r=$ Reliability Coefficient.

3.2 Pearson correlations between the five personality dimensions when treated separately and the creative behaviours of electrical and electronics teachers

The data presented in Table 2 provided information for answering research question two. The correlation analysis between the five personality dimensions when treated separately and the creative behaviours of electrical and electronics teachers in technical colleges. The table show that the five personality dimensions had the following results: Extraversion $(r=.947, \mathrm{p}<.05)$, agreeableness $(\mathrm{r}=$ $.802, \mathrm{p}<.05)$, consciousness $(\mathrm{r}=.744, \mathrm{p}<.05)$, openness $(\mathrm{r}=.702, \mathrm{p}<.05)$, and neuroticism $(\mathrm{r}=$ $.264, \mathrm{p}<.05)$. These imply that extraversion, agreeableness, consciousness and openness have a high positive correlation with the creative behaviours of electrical and electronics teachers in technical colleges in Nigeria. But neuroticism has a negative correlation with the creative behaviours of electrical and electronics teachers.

Table 2: Correlation analysis between the five personality dimensions when treated separately and the creative behaviours of electrical and electronics teacher is technical colleges

\begin{tabular}{lrrrrrr}
\hline \multicolumn{1}{c}{$\begin{array}{c}\text { Pearson } \\
\text { Correlation }\end{array}$} & KDOCS & Extraversion & Agreeableness & Consciousness & Neuroticism & Openness \\
\hline KDOCS & 1.000 & .947 & .802 & .744 & -.264 & .702 \\
Extraversion & .947 & 1.000 & .855 & .971 & -.422 & .815 \\
Agreeableness & .802 & .855 & 1.000 & .832 & -.080 & .854 \\
Consciousness & .744 & .971 & .832 & 1.000 & .896 & .783 \\
Neuroticism & -.264 & -.422 & -.080 & .896 & 1.000 & -.080 \\
Openness & .702 & .815 & .854 & .783 & -.080 & 1.000 \\
\hline
\end{tabular}

\subsection{Hypotheses testing}

The first hypothesis tested was; “The five personality dimensions treated together do not significantly correlate with the creative behaviours of electrical and electronics teachers in technical colleges in Nigeria." The result of the hypothesis testing is shown in Table 3. Table 3 shows the result of the multiple regression analysis between the five personality dimensions when treated together and the creative behaviours of electrical and electronics teachers in technical colleges in Nigeria. The result shows that F-ratio $(1,92)=341.017$, significant criterion (sig.) $=.000$ at $\mathrm{p}<.05$. Since the $\mathrm{p}$ value is less than .05 , it means that the five personality dimension traits have a positive statistically significant influence on the creative behaviours of electrical and electronics teachers in technical colleges in Nigeria. Therefore, the five personality dimensions treated together significantly correlate with the creative behaviours of electrical and electronics teachers in technical colleges in Nigeria.

Table 3: Multiple regressions analysis between the five personality dimensions when treated together and the creative behaviours of electrical and electronics teacher

\begin{tabular}{lrrrrrr}
\hline \multicolumn{1}{c}{ Model } & Sum of Squares & Df & $\begin{array}{c}\text { Mean } \\
\text { Square }\end{array}$ & F & p-value & Remark \\
\hline Regression & 23.479 & 1 & 23.479 & 341.017 & $.000^{\mathrm{b}}$ & Significant \\
Residual & 6.334 & 92 & .069 & & & \\
Total & 29.813 & 93 & & & & \\
\hline
\end{tabular}

a. Dependent Variable: KDOCS, b. Predictors: (Constant), GBFI 
The second hypothesis tested was, "The five personality dimensions treated separately do not significantly correlate with the creative behaviours of electrical and electronics teachers in technical colleges in Nigeria." Table 4 shows the result of the multiple regression analysis between the five personality dimensions when treated separately and the creative behaviours of electrical and electronics teachers in technical colleges in Nigeria. From the table, each of the five personality dimensions had the following results: Extraversion $(\beta=.925, \mathrm{t}=9.886$, sig. $=.002, \mathrm{p}<$ $.05)$, agreeableness $(\beta=.282, \mathrm{t}=4.321$, sig. $=.003, \mathrm{p}<.05)$, consciousness $(\beta=-.101, \mathrm{t}=3.881$, sig. $=.043, \mathrm{p}<.05)$, openness $(\beta=.320, \mathrm{t}=3.101$, sig. $=.006, \mathrm{p}<.05)$, and neuroticism $(\beta=-.192, \mathrm{t}=-$ 1.858 , sig. $=.076, \mathrm{p}<.05$ ). Since the significance criterion (sig.) for extraversion, agreeableness, consciousness and openness are less than the p-value of .05, it reveals that extraversion, agreeableness, consciousness and openness have a positive significant influence on the creative behaviours of electrical and electronics teachers in technical colleges. However, with neuroticism having sig. $=.076$ which is greater than p-value of .005 , it means it does not significantly influence the creative behaviours of electrical and electronics teachers in technical colleges in Nigeria.

Table 3: Multiple regression analysis between the five personality dimensions when treated separately and the creative behaviours of electrical and electronics teacher

\begin{tabular}{lrrrrr}
\hline \multicolumn{1}{c}{ Model } & \multicolumn{2}{c}{ Unstandardized Coefficients } & $\begin{array}{c}\text { Standardized } \\
\text { Coefficients } \\
\text { Beta }\end{array}$ & t & p-value \\
\hline (Constant) & \multicolumn{1}{c}{ Std. Error } & 8.632 & & 2.545 & .000 \\
Extraversion & 11.608 & .083 & .925 & 9.886 & .002 \\
Agreeableness & .820 & .076 & .282 & 4.321 & .003 \\
Consciousness & .333 & .119 & -.101 & 3.881 & .043 \\
Openness & .105 & .185 & .320 & 3.101 & .006 \\
Neuroticism & .573 & .084 & -.192 & -1.858 & .076 \\
\hline
\end{tabular}

\section{DISCUSSIONS}

Finding from this study indicated that there is a high positive correlation between the five personality dimensions when treated together and the creative behaviours of electrical and electronics teachers in technical colleges in Nigeria. This finding is in conformity with the finding of Bandura (2012) who revealed that there is correlation between the five personality dimensions and the creative behaviour teachers in the social sciences. Also, Darr (2009) reported that the five personality dimensions correlate strongly with the creative behaviour of military men. Raymond and Hassan (2016) hinted that there is a positive relationship between emotional intelligence (an aspect of personality) and teachers' practical skills performance in Radio, Television and Electronic Work (an electrical and electronics trade). Although, Mamta (2013) found no correlation between personality traits and creativity, this however does not invalidate the result of this study because as personality traits have been generally known to impact human characteristic behaviours such as creativity (Ivcevic \& Mayer, 2006). The implication of this is that when electrical and electronics teachers with high score on the five personality dimensions inventory are recruited to teach trades in technical colleges, there would be effective skill transfer in electrical and electronics trades in technical colleges.

In addition, the results revealed that there is a high positive correlation between the five personality dimensions when treated separately and the creative behaviours of electrical and electronics teachers in technical colleges in Nigeria. With the exception of neuroticism which had a low negative correlation with creative behaviour. This agrees with the findings of Yesil and Sozbilir (2013) who reported that there is a link between personality and individual innovation behaviour in the workplace when treated. Also, Iruloh and Ukaegbu (2015) found out when the five personality dimensions were treated separately and correlated with the creative behaviours of teachers, those of them high in agreeableness and extraversion were able to foster good interpersonal relationships; which afforded them the opportunity to understand the emotions and feelings of others, and so were effective in their work in the classroom. This therefore imply that teachers of electrical and electronics trades who score highly on the personality trait inventory, would make highly creative teachers, which is what the technical college system in a country like Nigeria urgently needs. 
In the same vein, the results indicated that the five personality dimension traits treated together have a positive statistically significant influence on the creative behaviours of electrical and electronics teachers in technical colleges in Nigeria. This agrees with Stajkovic et al. (2018) who found out that the big five personality traits influence self-efficacy (which are a function of creative behaviours) and academic performance. Similarly, this finding is supported by Zaidi et al. (2013) who reported that teachers who are high on personality traits are sociable, empathetic, believing, orderly, satisfied, inventive and unconventional which are the characteristics that are expected of a good and effective teacher. This does not come as a surprise because a teacher's high score on the five personality dimensions inventory is could only imply that such a teacher would be a high value resource for effective skill transfer in a given electrical and electronics trade in technical colleges.

Similarly, four (extraversion, agreeableness, consciousness and openness) out of the five personality dimensions when treated separately, significantly correlate with the creative behaviours of electrical and electronics teachers in technical colleges in Nigeria. Similar findings were reported by Karwowski et al. (2013) who hinted that both creative self-efficacy and creative personal identity have the strong positive correlations with extraversion, agreeableness, consciousness and openness, but the strongest negative correlation with neuroticism. Similarly, Iruloh and Ukaegbu (2015) hinted that those high in agreeableness and extraversion personality traits make good interpersonal relationships; which afford them the opportunity to understand the emotions and feelings of others. It is therefore means that teachers who would be effective in teaching trade subjects, especially in electrical and electronics related discipline, at the technical college level need to be creative in their approach.

\section{CONCLUSION AND RECOMMENDATIONS}

The five personality dimensions of electrical and electronics trades teacher correlates strongly with their creative behaviours. Extraversion, agreeableness, consciousness and openness contribute to electrical and electronics trades teacher creative behaviours. Hence the five personality dimensions are key traits needed by electrical and electronics trades teacher in order for them to be highly creative. Which is an important feature of an effective teacher in the twenty-first century. In the light of the findings of this study we recommend that: Science and Technical Boards and similar agencies in charge of the recruitment of trades' teachers in technical colleges in Nigeria should consider incorporating personality inventories in the screening process of such teachers in order to engage only the most creative ones among them; Training programmes, workshops, seminars and conferences should be organised and electrical and electronics trades teacher already in the technical college teaching service, in order to help them develop more positive personalities which would in turn enhance their creative behaviours; Facilities and the necessary infrastructure should be provided in technical colleges in order to give electrical and electronics trades teachers the needed support to express themselves creatively; A reward and incentive systems should be put in place, for the encouragement of creativity among electrical and electronics teachers in technical colleges in Nigeria.

\section{References}

American psychological Association, (2018). Personality. Retrieved on 14 April, 2018 from http://www.apa.org/topics/personality/.

Anderson, N., Potočnik, K., \& Zhou, J. (2014). Innovation and creativity in organizations: A state-of-the-science review, prospective commentary, and guiding framework. Journal of Management, 40(5), 1297-1333.

Ashraf, S., Bano, H., Ilyas, A., \& Rehman, F. A. (2013). Students’ preferences for the teachers' characteristics and traits in character building of students with special needs. Mediterranean Journal of Social Sciences, 4(4), 423-430.

Bettencourt, L. A., Gwinner, K. P., \& Meuter, M. L. (2001). A comparison of attitude, personality, and knowledge predictors of service-oriented organizational citizenship behaviors. Journal of Applied Psychology, 86(1), 29.

Bui, H. T. (2017). Big Five personality traits and job satisfaction: Evidence from a national sample. Journal of General Management, 42(3), 21-30. 
Corr, P. J., \& Matthews, G. (Eds.). (2009). The Cambridge handbook of personality psychology (pp. 748-763). Cambridge: Cambridge University Press.

Darr, W. (2009). Big five personality research in the military: a meta-analysis. DGMPRA TM 2009, 23.

Emesini, N. O. (2016). Empowering of students in technical colleges in Nigeria with trade skills for selfreliance to enhance sustainable development. British Journal of Education, 4(9), 46-54.

Federal Republic of Nigeria, (2013). National policy on education. Lagos. NERDC Press. Funder, D. C. (2004). The Personality puzzle (3rd ed.). New York: Maguire and Co.

Furnham, A., Eracleous, A., \& Chamorro-Premuzic, T. (2009). Personality, motivation and job satisfaction: Hertzberg meets the Big Five. Journal of Managerial Psychology, 24(8), 765-779.

Grant, A. M., \& Berry, J. W. (2011). The necessity of others is the mother of invention: Intrinsic and prosocial motivations, perspective taking, and creativity. Academy of Management Journal, 54(1), 73-96.

Gurven, M., Von Rueden, C., Massenkoff, M., Kaplan, H., \& Lero Vie, M. (2013). How universal is the big five? testing the five-factor model of personality variation among forager-farmers in the Bolivian Amazon. Journal of personality and social psychology, 104(2), 354.

Iruloh, B. R. N., \& Ukaegbu, H. M. (2015). Big five personality traits as predictors of emotional intelligence of secondary school teachers in Rivers State of Nigeria. European Journal of Psychological

Research, 2(2), 52-59.

Ivcevic, Z., \& Mayer, J. D. (2006). Creative types and personality. Imagination, Cognition And Personality, 26(1), 65-86.

Karwowski, M., Lebuda, I., Wisniewska, E., \& Gralewski, J. (2013). Big five personality traits as the predictors of creative self-efficacy and creative personal identity: does gender matter? The Journal of Creative Behaviour, 47(3), 215-232.

Kaufman, J. C. (2012). Counting the muses: development of the kaufman domains of creativity scale (KDOCS). Psychology of Aesthetics, Creativity, and the Arts, 6(4), 298-308. Doi: 10.1037/a0029751.

Kaufman, J. C., Pumaccahua, T. T., \& Holt, R. E. (2013). Personality and creativity in realistic, investigative, artistic, social, and enterprising college majors. Personality and Individual Differences, 54(8), 913-917.

Kaufman, S. B., Quilty, L. C., Grazioplene, R. G., Hirsh, J. B., Gray, J. R., Peterson, J. B., \& DeYoung, C. G. (2016). Openness to experience and intellect differentially predict creative achievement in the arts and sciences. Journal of Personality, 84(2), 248-258.

Kolstad, A. (2013). Human psychological characteristics versus animal characteristics. Psychology, 4(5), $488-$ 493.

Krishnan, R., Ismail, S., Loon, K. W., \& Muthusamy, G. (2017). The moderating effect of employee personality in the relationship between job design characteristics and organizational citizenship behaviour. The Social Sciences, 12(6), 1014-1023.

Larsen, R. J., \& Buss, D. M. (2005). Personality psychology: Domains of knowledge about human nature (2nd Ed.). New York: McGraw Hill.

Madamet, A., Potard, C., Huart, I., El-Hage, W., \& Courtois, R. (2017). Relationship between the Big Five personality traits and PTSD among French police officers. European Journal of Trauma \& Dissociation. https://doi.org/10.1016/j.ejtd.2017.11.001.

Maher, M. L., Merrick, K. E., \& Saunders, R. (2008). Achieving creative behaviour using curious learning agents. Creative Intelligent Systems, 8, 40-46.

Mamta R. (2013). A comparative study of the relationship between emotional intelligence and teacher effectiveness of degree and B.Ed college teachers of Rajasthan in relation to gender. Indian Streams Research Journal, 2(12), 1-5.

Matteson, M. L., \& Kennedy, S. (2016). The relationship between trait affect and job attitudes in library employees. Journal of Library Administration, 56(7), 810-822.

Mayer, J. D. (2007). Personality: A systems approach. Boston: Allyn \& Bacon.

McCrae, R. R., \& Löckenhoff, C. E. (2010). Self-regulation and the five-factor model of personality traits. Handbook of Personality and Self-Regulation, 145-168.

Mendonca, M. R. (2016). Relating big five factor model to the acceptance and use of on-line Shopping. International Journal of Marketing Studies, 8(3), 89-98.

National Board for Technical Education (NBTE), (2001). National technical certificate and advanced

national technical certificate curriculum and course specifications for Electrical \& electronic trades. Kaduna. NBTE.

O’Connell, M., \& Sheikh, H. (2011). Big Five personality dimensions and social attainment: evidence from beyond the campus. Personality and Individual Differences, 50(6), 828-833.

O’Sullivan, D., Strauser, D. R., \& Wong, A. W. (2012). Five-Factor Model of Personality, Work Behaviour Self Efficacy, and length of prior employment for individuals with disabilities: an exploratory analysis. Rehabilitation Counselling Bulletin, 5(3), 156-165. 
Okwelle, P. C. \& Okeke, B. (2012). Development and validation of instrument for assessing practical skills in fault diagnoses and repairs of radio and television systems in Nigerian technical colleges. American Journal of Scientific and Industrial Research, 3(3), 181-190. doi:10.5251/ajsir.2012.3.3.181.190.

Patterson, F., Kerrin, M., \& Gatto-Roissard, G. (2009). Characteristics and behaviours of innovative people in organisations. Literature Review prepared for the NESTA Policy \& Research Unit, 1-63.

Pervin, L. A., Cervone, D., \& John, O. P. (2005). Personality: Theory and Research (9 $9^{\text {th }}$ ed.). Hoboken, NJ: John Wiley \& Sons.

Raymond, E., \& Hassan J. Y. (2016). Relationship between emotional intelligence and teachers’ practical skills performance in radio, television and electronic work. British Journal of Education, Society and Behavioural Science, 13(2), 1-9.

Setiadi, N. J., \& Aryanto, R. (2014). Creativity-relevant personal characteristics among Indonesia creative workers. The Winners, 15(2), 140-149.

Sharp, C. (2004). Developing young children's creativity: what can we learn from research? Readership, Autumn, 2004(34), 1-11.

Soto, C. J., \& Jackson, J. J. (2013). Five-factor Model of Personality. In D. S. Dunn (Ed.), Oxford Bibliographies in Psychology. New York, Oxford University Press.

Stajkovic, A. D., Bandura, A., Locke, E. A., Lee, D., \& Sergent, K. (2018). Test of three conceptual models of influence of the big five personality traits and self-efficacy on academic performance: A meta-analytic path-analysis. Personality and Individual Differences, 120, 238-245.

Stanley, T. (2016). Work Environments, Creative Behaviours, and Employee Engagement (Doctoral dissertation). Queensland University of Technology, Australia.

Templer, K. J. (2012). Five-factor model of personality and job satisfaction: The importance of agreeableness in a tight and collectivistic Asian society. Applied Psychology, 61(1), 114-129.

Vasudevan, H. (2013). The influence of teachers' creativity, attitude and commitment on students' proficiency of the english language. IOSR Journal of Research \& Method in Education (IOSR-JRME), 1(2), 12-19.

Widiger, T. A., \& Costa, P. T. (2012). Integrating normal and abnormal personality structure: the five-factor model. Journal of Personality, 80(6), 1471-1506.

Widiger, T. A., \& Oltmanns, J. R. (2017). Neuroticism is a fundamental domain of personality with enormous public health implications. World Psychiatry, 16(2), 144-145.

Wille, B., Hofmans, J., Feys, M., \& De Fruyt, F. (2014). Maturation of work attitudes: correlated change with

big five personality traits and reciprocal effects over 15 years. Journal of Organizational Behaviour, 35(4), 507-529.

Yesil, S., \& Sozbilir, F. (2013). An empirical investigation into the impact of personality on individual innovation behaviour in the workplace. Procedia-Social and Behavioural Sciences, 81, 540-551.

Zaidi, N. R., Wajid, R. A., Zaidi, F. B., Zaidi, G. B., \& Zaidi, M. T. (2013). The big five personality traits and their relationship with work engagement among public sector university teachers of Lahore, African Journal of Business Management, 7(15), 1344-1353. Doi:10.5897/AJBM12.290. 